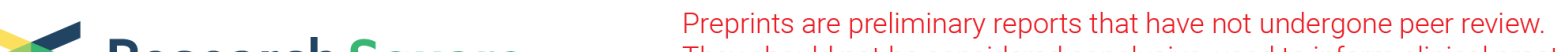 Research Square They should not be considered conclusive, used to inform clinical practice, or referenced by the media as validated information.
}

\section{JQ1 Attenuates Neuroinflammation by Inhibiting Inflammasome-Dependent Canonical Pyroptosis Pathway in Sepsis-Associated Encephalopathy}

\section{Xiaolin Zhong}

The first Affiliated hospital of university of South China

\section{Zuyao Chen}

The first affiliated hospital of university of South China

\section{Yajuan Wang}

The first Affiliated Hospital of University of South China

\section{Mingli Mao}

The First Affiniated hospital of University of South China

\section{Yingcheng Deng}

Hengyang Medical College: University of South China

\section{Mengmeng Shi}

Hengyang Medical College: University of South China

\section{Yang Xu}

Hengyang Medical College: University of South China

\section{Ling Chen}

The first affiliated hospital of university of South China

Wenyu Cao ( $\square$ marksman0@163.com )

Hengyang Medical College: University of South China https://orcid.org/0000-0001-7971-3326

\section{Research Article}

Keywords: Sepsis-associated encephalopathy (SAE) , Neuroinflammation, Pyroptosis, Bromodomaincontaining protein 4 (BRD4), JQ1

Posted Date: September 28th, 2021

DOI: https://doi.org/10.21203/rs.3.rs-872172/v1

License: (1) (1) This work is licensed under a Creative Commons Attribution 4.0 International License. Read Full License 


\section{Abstract}

Sepsis-associated encephalopathy (SAE) is manifested clinically in hyperneuroinflammation and associated with increased morbidity worldwide. Pyroptosis, a novel programmed cell death, has been considered as a causative factor of SAE. Bromodomain-containing protein 4 (BRD4) is a member of the Bromo and Extra-Terminal (BET) family, and promotes inflammatory response in various diseases. Thereby, we examined the effect of JQ1, which is a specific selective inhibitor of BRD4, on the inflammasome-induced pyroptosis of hippocampus in sepsis mice model induced by lipopolysaccharide (LPS) treatment. And we found that JQ1 treatment inhibited the phosphorylation of BRD4, alleviated weight loss and splenomegaly, as well as decreased the serum levels of procalcitonin (PCT) and D-lactate dehydrogenase (D-LDH) induced by LPS injection. Moreover, JQ1 administration decreased the expression of nod-like receptor family protein 1 (NLRP1) or 3 (NLRP3) or the absent in melanoma 2 (Aim2) inflammasomes by blocking nuclear factor kappa B (NFKB) signaling in the hippocampus of sepsis mice. Interestingly, we found that JQ1 selectively attenuated the canonical pyroptosis pathway in SAE mice, indicating by reduced expression of Caspase-1, Caspase-11, gasdermin D (GSDMD) and gasdermin A (GSDMA). JQ1 intervention also suppressed the activation of hippocampal microglia and the release of pro-inflammatory factors, such as IL-1 $\beta$, IL-18 and IL-6 in SAE mice. In addition, JQ1 treatment protected blood brain barrier (BBB) by up-regulated the expression of tight junction protein occludin and ZO-1 in SAE mice. Furthermore, JQ1 administration remarkably rescued neuronal damage in SAE mice, as enhanced expression of hippocampal NeuN and Doublecortin (DCX). Thus, the protective effects of BRD4 inhibitor JQ1 on SAE were verified in neurons via the inhibition of canonical pyroptosis induced inflammation.

\section{Introduction}

Sepsis-associated encephalopathy (SAE) is a diffuse brain dysfunction associated with sepsis, which develops a wide variety of disorders in neural functions [1]. Neuroinflammation [2], loss of blood-brain barrier integrity, microglia activation, and neuronal death $[3,4]$ have been considered as causative factors of SAE, but the pathological changes of SAE are highly complex and multifactorial and still needed to be clarified. Therefore, it is vital to understand the physiopathology and molecular mechanism of SAE for searching a potential therapeutic strategy.

Pyroptosis, featured by cell membrane perforation and disintegration, is an inflammatory form of programmed cell death [5]. This type of cell death is recently suggested to be dependent on the nod-like receptor family protein 1 (NLRP1) or 3 (NLRP3) or the absent in melanoma 2 (Aim2) inflammasomedependent, which can further trigger the pyroptosis signaling pathways [6, 7]. Pyroptosis executed by a series of pore-forming proteins called Gasdermins superfamily (GSDMs) [8]. GSDMs have six protein subtypes, including gasdermin A (GSDMA), gasdermin B (GSDMB), gasdermin C (GSDMC), gasdermin D (GSDMD), gasdermin E (GSDME) and pejvakin (PJVK) proteins [9]. Except for PJVK, all members of the GSDM superfamily contain a conserved two-domain structure: $\mathrm{N}$-terminal and $\mathrm{C}$-terminal domains. When the N-terminal domain of these GSDMs is released, it possesses pore-forming activity to cause 
inflammatory death associated with the loss of cell membrane integrity and release of inflammatory mediators [9]. Currently, GSDMD [10] and GSDMA [11] are confirmed to be cleaved by Caspase-1/11 and both of which mediate canonical pyroptosis pathway. GSDMC is specifically cleaved by Caspase-8 and mediates non-canonical pyroptosis pathway [12], while GSDME is similarly cleaved by Caspase-3, converting apoptosis to pyroptosis [10]. Accumulating evidence indicates that pyroptosis is induced in central nervous system disease including traumatic brain injury (TBI) [13], multiple sclerosis (MS) [14] and Alzheimer's disease (AD) [15]. Blocking pyroptotic cell death has been proved to be neuro-protective in rodents $[16,17]$, thus, illuminating the pyroptotic mechanism would benefit for the development of a cure in those diseases.

Bromodomain-containing protein 4 (BRD4) is an important transcriptional regulator of NF-KB-dependent inflammatory gene expression [18]. Inhibition of BRD4 by small molecules, such as JQ1, suppresses NF$\mathrm{KB}$-dependent inflammatory gene expression [19-21]. Mice deficient of BRD4 in myeloid-lineage cells is resistant to LPS-induced sepsis [22]. Phosphorylation of BRD4 (p-BRD4) is critical for its binding to the promotor region of genes [23], and recent study shows that p-BRD4 is involved in neuroplasticity [24]. However, it remains unclear if altered BRD4 or p-BRD4 contributes to pyroptosis of SAE, and whether BRD4 inhibition can reverse this process.

In this study, we found that up-regulated hippocampal expression of BRD4 and p-BRD4 was associated with SAE in mice. Blunting BRD4 by JQ1 alleviated inflammasome-induced pyroptosis, microglia activation and neuroinflammation. Furthermore, JQ1 administration could maintain the blood brain barrier by enhancing tight junction, inhibit neuronal death, as well as protect hippocampal neurogenesis. These results indicate that BRD4 might serve as a promising therapeutic target for SAE.

\section{Materials And Methods}

\section{Animals}

Adult male C57BL/6 mice weighing 25-30 g (obtained from the Hunan SJA Lab Animal Center of Changsha, Hunan, China) were used in this study. Mice were group-housed (4-8 mice per cage) at a controlled temperature $\left(22 \pm 2^{\circ} \mathrm{C}\right)$ under a 12-h light/dark cycle with free access to food and water. The mice adapted to their new environment for 14 days. The experimental protocol was approved by the Animal Care and Use Committee of the University of South China and conformed to the National Institutes of Health Guide for the Care and Use of Laboratory Animals.

\section{Drugs}

LPS from Escherichia coli 026: B8 (Sigma, USA) was dissolved in $0.9 \% \mathrm{NaCl}$. Based on a previous study [25], mice were treated with a single i.p. injection of LPS $(10 \mathrm{mg} / \mathrm{kg})$ to establish the animal model of SAE [26], and an equal volume of saline was administered to another cohort of mice as a vehicle control group. BRD4 inhibition was applied by i.p. pretreatment with $50 \mathrm{mg} / \mathrm{kg}$ JQ1 (MCE, Shanghai, China) for 1 $\mathrm{h}$ before LPS injection, and an equal volume of DMSO was administered as a control group. 


\section{ELISA detection}

Mice Procalcitonin (PCT) and D-lactate dehydrogenase (D-LDH) ELISA Kits (CUSABIO, WuHan, China) were used to determine the PCT and D-LDH levels, which are the diagnosis and monitoring markers as sepsis. According to the manufacturer's instructions, $24 \mathrm{~h}$ after the LPS injection, mice were decapitated and eyeball blood was collected and centrifuged for $20 \mathrm{~min}$ at $1500 \mathrm{~g}$ at room temperature. The supernatants were collected and used to measure the PCT and D-LDH levels of each sample. The plasma used to test PCT was diluted with Sample Diluent (1:30). Then $90 \mu$ of standard or sample was added to each well and incubate for $2 \mathrm{~h}$ at $37^{\circ} \mathrm{C}$, followed by $100 \mu \mathrm{l}$ of biotin-antibody was added to each well and incubated for $1 \mathrm{~h}$ at $37^{\circ} \mathrm{C}$ and $100 \mu \mathrm{l}$ of HRP-avidin was also added to each well and then incubate for $1 \mathrm{~h}$ at $37^{\circ} \mathrm{C}$. Aspirate and wash each well after incubation. Wells were then developed with TMB Substrate for $20 \mathrm{~min}$ at $37^{\circ} \mathrm{C}$ in dark. Stop solution was added to each well to terminate the reaction and the absorbance was measured at $450 \mathrm{~nm}$.

\section{Immunohistochemistry}

Mice were sacrificed $24 \mathrm{~h}$ after LPS injection by administration of an overdose of $10 \%$ chloral hydrate ( 80 $\mathrm{mg} / \mathrm{kg}$ ) and were then perfused transcardially with saline, followed by $100 \mathrm{ml}$ of ice-cold $4 \%$ paraformaldehyde solution ( $\mathrm{pH}$ 7.4). Brains were removed and fixed for $24 \mathrm{~h}$ in $4 \%$ paraformaldehyde, and cryoprotected with $15 \%$ and then $30 \%$ phosphate-buffered sucrose $(\mathrm{pH} \mathrm{7.4)}$ overnight. Coronal sections $(25 \mu \mathrm{m})$ of brains were made, and free-floating sections were treated with $3 \% \mathrm{H}_{2} \mathrm{O}_{2}$ to remove endogenous peroxidase, which was then blocked by placing sections in $5 \%$ normal sheep serum in 0.01 $\mathrm{M}$ phosphate-buffered saline (PBS) containing $0.1 \%$ Triton with $\mathrm{X}-100$ for $2 \mathrm{~h}$. Sections were then incubated with rabbit anti-BRD4 antibody (Bethyl, A301), rabbit anti-p-BRD4 (Millipore, ABE1451), rabbit anti-IBA1 (Abcam, ab5076), rabbit anti-NeuN (Millipore, MAB377) and rabbit anti-DCX (CST, 4604S) at room temperature for $2 \mathrm{~h}$, followed by incubation at $4^{\circ} \mathrm{C}$ overnight. Secondary reagents comprised biotinylated goat anti-rabbit IgG (Proteintech, China). Diaminobenzidine tetrahydrochloride (DAB) (ZSGB$\mathrm{BIO}$, China) was used as a peroxidase substrate. Washing for all procedures was accomplished in $0.01 \mathrm{M}$ PBS, except for the blocking step. The slices were captured using a digital camera that was attached to the microscope (Olympus, Japan), and the average optical density (OD) of the BRD4, p-BRD4, IBA1, NeuN and DCX immunoreactivity were detected in regions of DG by using Image $\mathrm{J}$ software (NIH, USA). In order to avoid any bias, the researcher quantifying the number was blinded to the treatment used.

\section{Western blotting}

Mice were anesthetized with an overdose of $10 \%$ sodium pentobarbital $(80 \mathrm{mg} / \mathrm{kg})$, and the hippocampus (HIP) were rapidly removed following decapitation. The samples were homogenized in a lysis buffer that contained phenylmethysulforyl fluoride (PMSF) (CWBIO). And the protein concentration was measured using a BCA Assay Kit (CWBIO). The sample extracts were then separated by sodium dodecyl sulfatepolyacrylamide gel electrophoresis (SDS-PAGE) at $90 \mathrm{~V}$ for $2 \mathrm{~h}$ and transferred onto PVDF membranes (Millipore) for $2 \mathrm{~h}$ at $200 \mathrm{~mA}$. Then, the membranes were blocked with $10 \%$ nonfat milk for $2 \mathrm{~h}$ at room temperature and incubated with the primary antibodies (Table 1) overnight in $5 \%$ skim milk solution at 
$4^{\circ} \mathrm{C}$. The next day, after washing three times in $0.02 \mathrm{M}$ Tween-Tris buffered solution, the membranes were incubated with horseradish peroxidase (HRP)-conjugated donkey anti-rabbit (1:3000, Millipore) or donkey anti-mouse (1:2000, CWBIO) polyclonal secondary antibodies for $1.5 \mathrm{~h}$ at room temperature. The signals were detected by an enhanced chemiluminescence (ECL) system (CWBIO). The protein levels were quantified by densitometry using $\mathrm{NIH}$ Image $(\mathrm{NIH}$, Bethesda, MD, USA).

Table 1

Information for the primary antibodies used in this study

\begin{tabular}{|c|c|c|c|c|}
\hline Antibody & Company & Lot number & Moleculer weight (KD) & Dilution ratio \\
\hline BRD4 & Abclonal & WH113278 & 150 & $1: 500$ \\
\hline NF-kB & Proteintech & 10745-1-AP & 65 & $1: 500$ \\
\hline NLRP1 & Abclonal & A16212 & 160 & $1: 1000$ \\
\hline NLRP3 & CST & 15101S & 110 & $1: 500$ \\
\hline AIM2 & Abclonal & A3356 & 47 & $1: 1000$ \\
\hline ASC & Santan Cruze & Sc-514414 & 24 & $1: 500$ \\
\hline Caspase-1 & Santan Cruze & Sc-56036 & $45,20-22$ & $1: 500$ \\
\hline Caspase-11 & Abclonal & A6495 & 30 & $1: 500$ \\
\hline GSDMD & Abclonal & A18281 & 53 & $1: 1000$ \\
\hline GSDMA & Abcam & Ab181027 & 49 & $1: 1000$ \\
\hline Caspase-8 & Proteintech & 13423-1-AP & $32-45 / 53-57$ & $1: 500$ \\
\hline GSDMC & Abclonal & A14550 & 58 & $1: 1000$ \\
\hline Caspase-3 & CST & $9662 S$ & $17,19,35$ & $1: 1000$ \\
\hline GSDME & Proteintech & 13075-1-AP & 55 & $1: 1000$ \\
\hline CD68 & Proteintech & 28058-1-AP & 100 & $1: 500$ \\
\hline IL-1 $\beta$ & Proteintech & 16806-1-AP & $30-35$ & $1: 500$ \\
\hline IL-18 & Proteintech & 10663-1-AP & 22 & $1: 500$ \\
\hline IL-6 & Proteintech & 21865-1-AP & 24 & $1: 500$ \\
\hline occludin & Proteintech & 27260-1-AP & 59 & $1: 1000$ \\
\hline ZO-1 & Proteintech & 21773-1-AP & 220 & $1: 1000$ \\
\hline NeuN & CST & $24307 S$ & $46-55$ & $1: 1000$ \\
\hline$\beta$-Actin & Proteintech & 60008-1-lg & 42 & $1: 3000$ \\
\hline
\end{tabular}


Mice hippocampus total RNA was extracted by Trizol® reagent (CWBIO) according to the manufacturer's instructions. The RNA purity was determined by the A260 nm/A280 nm absorption ratio. cDNA synthesis was performed with the RevertAid ${ }^{\text {TM }}$ First Strand CDNA Synthesis Kit (Fermentas) according to the manufacturer's instructions using $2 \mu \mathrm{g}$ of total RNA. Gene expression was determined by an ABI-7500 real-time PCR system with TB Green ${ }^{\text {TM }}$ Premix Ex Taq ${ }^{\text {TM }}$ II (Takara). The primers were designed with Primer 3 software (Table 2). A two-step PCR protocol was used according to the manufacturer's instructions. The PCR cycling conditions were $30 \mathrm{~s}$ at $95^{\circ} \mathrm{C}$ followed by 40 cycles at $95^{\circ} \mathrm{C}$ for $5 \mathrm{~s}$ and $60^{\circ} \mathrm{C}$ for $45 \mathrm{~s}$. The samples were processed in technical duplicates, and a melting analysis was performed for each sample at the end of PCR. The $2^{-\triangle \triangle C t}$ method was used to determine the relative gene expression as described in our previous study [27]. 
Table 2

Information for the primers used in this study

\begin{tabular}{|c|c|c|}
\hline Genes & Primers & Sequence $5^{\prime}-3^{\prime}$ \\
\hline \multirow[t]{2}{*}{ BRD4 } & forward & СССTTTTCTGCTCATATTCAGC \\
\hline & reverse & AATGTATCATAAGCGGAGAGGG \\
\hline \multirow[t]{2}{*}{ NLRP1 } & forward & GCCTCACАTCCACATАСTGCTCAC \\
\hline & reverse & AGCTCTGCAATCACTTGGTCACTG \\
\hline \multirow[t]{2}{*}{ NLRP3 } & forward & CGTTGCAAGCTGGCTCAGTA \\
\hline & reverse & GGGGACTGGGATACAGCCTT \\
\hline \multirow[t]{2}{*}{ AIM2 } & forward & CTGCCGCCATGCTTCCTTAACTAG \\
\hline & reverse & AGCAGTCCAGTTCGGTAGTGTAGG \\
\hline \multirow[t]{2}{*}{ ASC } & forward & ACAATGACTGTGCTTAGAGACA \\
\hline & reverse & CACAGCTCCAGACTCTTCTTTA \\
\hline \multirow[t]{2}{*}{ Caspase-1 } & forward & AGAGGATTTCTTAACGGATGCA \\
\hline & reverse & TCACAAGACCAGGCATATTCTT \\
\hline \multirow[t]{2}{*}{ Caspase-11 } & forward & ATGCTTCTCCAGACATTCTTCA \\
\hline & reverse & TGGCCTCCTTTATTGGGTAAAT \\
\hline \multirow[t]{2}{*}{ GSDMD } & forward & CTAGCTAAGGCTCTGGAGACAA \\
\hline & reverse & GATTCTTTTCATCCCAGCAGTC \\
\hline \multirow[t]{2}{*}{ GSDMA } & forward & GAACTTGCACAAGGAGAGGAAA \\
\hline & reverse & CATCACCACATAGAGGTTCTCC \\
\hline \multirow[t]{2}{*}{ Caspase-8 } & forward & ACCAAATGAAGAACAAACCTCG \\
\hline & reverse & СTTCATTTTTCGGAGTTGGGTT \\
\hline \multirow[t]{2}{*}{ GSDMC } & forward & ССTTTCCAATGAGATTTGTGGG \\
\hline & reverse & GGAAACTGGAGAACACAACTTC \\
\hline \multirow[t]{2}{*}{ Caspase-3 } & forward & GAAACTCTTCATCATTCAGGCC \\
\hline & reverse & GCGAGTGAGAATGTGCATAAAT \\
\hline \multirow[t]{2}{*}{ GSDME } & forward & GAGAGTCACTCTTCGTTTGGAA \\
\hline & reverse & CTGAAGTACCAGGTTGTCCATA \\
\hline
\end{tabular}




\begin{tabular}{|c|c|c|}
\hline Genes & Primers & Sequence $5^{\prime}-3^{\prime}$ \\
\hline \multirow[t]{2}{*}{ CD68 } & forward & GAAATGTCACAGTTCACACCAG \\
\hline & reverse & GGATCTTGGACTAGTAGCAGTG \\
\hline \multirow[t]{2}{*}{ IL-1 $\beta$} & forward & GCAGAGCACAAGCCTGTCTTCC \\
\hline & reverse & АCCTGTCTTGGCCGAGGACTAAG \\
\hline \multirow[t]{2}{*}{ IL-18 } & forward & CTGTTGGCCCAATTACTAACAG \\
\hline & reverse & TCCCGAATTGGAAAGGGAAATA \\
\hline \multirow[t]{2}{*}{ II-6 } & forward & СTCCCAACAGACCTGTCTATAC \\
\hline & reverse & CCATTGCACAACTCTTTTCTCA \\
\hline \multirow[t]{2}{*}{ GAPDH } & forward & ACCACCATGGAGAAGGCTGG \\
\hline & reverse & CTCAGTGTAGCCCAGGATGC \\
\hline
\end{tabular}

\section{Statistical analyses}

All statistical analyses were conducted with GraphPad Prism 5.0 software (GraphPad Software, San Diego, CA, USA). Data are presented as the mean \pm SEM. Significant differences were determined using ANOVAs followed by Bonferroni's post hoc testing for three groups. $p<0.05$ was considered statistically significant.

\section{Results}

\section{JQ1 treatment inhibits the phosphorylation of BRD4 and prevents LPS-induced sepsis-related symptoms in mice}

High dose lipopolysaccharide (LPS) could induce sepsis and sepsis-associated encephalopathy [25]. In the present study, we explore the expression of BRD4 and p-BRD4 in the hippocampus of mice, which is a main region susceptibility to sepsis. Real-Time PCR showed that there was significantly differences among the groups in the mRNA level of BRD4 $\left(F_{(2,15)}=12.94, p=0.0008\right.$, Figure. $\left.1 \mathrm{~A}\right)$. Bonferroni post-test analysis revealed that the mRNA level of BRD4 in DMSO + LPS mice increased when compared with those of the DMSO + NS group $(t=4.927, p<0.001)$, which was reversed by JQ1 treatment $(t=3.657, p<$ 0.01). Western blot was used to detect the protein level of BRD4, and one-way ANOVA suggested that there were significantly differences among the groups in the protein level of BRD4 $\left(F_{(2,11)}=17.29, p<\right.$ 0.001 , Figure. $1 \mathrm{~B}$ and $1 \mathrm{C})$. Bonferroni post-test analysis revealed that when compared with the DMSO + NS group, the protein level of BRD4 in DMSO + LPS mice increased significantly $(t=4.927, p<0.01)$, which was reversed by JQ1 treatment $(t=5.242, p<0.01)$. Furthermore, we investigated the expression of BRD4 and p-BRD4 by immunohistochemistry, and the representative images of BRD4 and p-BRD4positive cells are shown in Figure. 1D. The analysis results show that there were significantly differences 
among the groups in the average optical density (OD) of $\operatorname{BRD} 4\left(\mathrm{~F}_{(2,19)}=8.053, p=0.0035\right.$, Figure. 1E) and $\mathrm{p}$-BRD4 $\left(\mathrm{F}_{(2,44)}=8.952, p=0.0006\right.$, Figure. 1E). Bonferroni post-test analysis revealed that LPS challenge could increase the expression of hippocampal BRD4 $(t=3.764, p<0.001)$ and $p$-BRD4 $(t=2.794, p<0.05)$, but JQ1 administration could decrease the expression of BRD4 $(t=2.872, p<0.05)$ and $p-B R D 4(t=4.096$, $p<0.001)$. These results suggested that JQ1 treatment not only inhibited the expression of BRD4, but also repressed the phosphorylation of BRD4.

Sepsis exhibited weight loss and splenomegaly. In the present study, the body weight and spleen weight of DMSO + NS, DMSO + LPS and JQ1 + LPS group mice were also determined. Two-way ANOVA with Bonferroni post-test analysis revealed that $24 \mathrm{~h}$ after LPS injection, the body weight of mice decreased when compared with the NS group $(t=3.403, p<0.01)$, but no significant difference was found between the DMSO + NS groups and JQ1 + LPS mice $(\mathrm{t}=1.232, p>0.05$, Figure. 1F). One-way ANOVA indicated there was a significant difference among the groups in the spleen weight/body weight $\left(\mathrm{F}_{(2,20)}=25.99, p<\right.$ 0.001 , Figure. $1 \mathrm{G}$ ). Bonferroni post-test analysis revealed that the spleen weight/body weight in DMSO + LPS mice increased when compared with those of the DMSO + NS group ( $t=5.806, p<0.001)$, which was rescued by JQ1 treatment $(t=6.592, p<0.001)$. These results suggested that JQ1 could inhibit weight loss and splenomegaly induced by LPS administration.

Procalcitonin (PCT) and D-lactate dehydrogenase (D-LDH) levels are the diagnosis and monitoring markers in sepsis. So we also detected the levels of serum PCT and D-LDH by using ELISA kits. One-way ANOVA suggested that there were significantly differences among the groups in the levels of PCT $\left(F_{(2,16)}\right.$ $=4.046, p=0.0076$, Figure. $1 \mathrm{H})$ and D-LDH $\left(\mathrm{F}_{(2,18)}=10.55, p=0.0012\right.$, Figure. 1I). Bonferroni post-test analysis revealed that LPS caused increased PCT level $(t=3.694, p<0.01)$ and D-LDH level $(t=4.349, p<$ $0.01)$ compared to NS mice, these effects were effectively attenuated by JQ1 treatment ( $P C T(t=2.779$, $p<0.05)$ and $\mathrm{D}-\mathrm{LDH}(\mathrm{t}=3.116, p<0.05))$. These results indicated that JQ1 could prevent the process of sepsis induced by LPS administration.

\section{JQ1 treatment inhibits LPS-induced the activation of NF-KB and inflammasomes}

Inflammasomes, mainly including NLRP1, NLRP3 and Aim2, play an important role in triggering pyroptosis and inflammatory response in SAE [28]. To determine the role of JQ1 treatment on the activation of the inflammasomes, we examined the alterations of mRNA levels of NLRP1, NLRP3, Aim2 and ASC in the hippocampus of mice. One-way ANOVA suggested that there were significantly differences among the groups in the mRNA level of NLRP1 $\left(F_{(2,16)}=26.28, p<0.0001\right), \operatorname{NLRP3}\left(F_{(2,17)}=\right.$ $11.86, p=0.0008)$, Aim2 $\left(\mathrm{F}_{(2,16)}=6.822, p=0.0085\right)$ and $\operatorname{ASC}\left(\mathrm{F}_{(2,17)}=14.93, p=0.0003\right)$ (Figure. $\left.2 \mathrm{~A}\right)$. Bonferroni post-test analysis revealed that LPS increased the mRNA level of NLRP1 $(t=5.312, p<0.001)$, NLRP3 $(t=4.855, p<0.01)$, Aim2 $(t=3.113, p<0.05)$ and ASC $(t=4.346, p<0.01)$ compared to NS mice, while JQ1 treatment decreased the levels of NLRP1 $(t=2.791, p<0.001)$, NLRP3 $(t=2.758, p<0.05)$, Aim2 $(t=3.232, p<0.05)$ and ASC $(t=5.047, p<0.001)$ compared to those LPS mice. 
Nuclear factor-KB (NF-kB) signaling pathway was found to be involved in LPS-induced inflammatory response [29]. Furthermore, western blotting was used to determine the protein levels of NF-KB, NLRP1, NLRP3, Aim2 and ASC in the hippocampus of mice. One-way ANOVA suggested that there were significantly differences among the groups in the protein level of NF-KB $\left(\mathrm{F}_{(2,11)}=12.89, p=0.0023\right)$, $\operatorname{NLRP1}\left(\mathrm{F}_{(2,11)}=18.14, p=0.0007\right), \operatorname{NLRP} 3\left(\mathrm{~F}_{(2,11)}=10.21, p=0.0048\right), \operatorname{Aim} 2\left(\mathrm{~F}_{(2,11)}=22.04, p=0.0003\right)$ and ASC $\left(F_{(2,11)}=11.95, p=0.0029\right)$ ( Figure. $2 B$ and $2 C$ ). Bonferroni post-test analysis revealed that LPS increased the protein level of NF-KB $(\mathrm{t}=3.540, p<0.05)$, NLRP1 $(\mathrm{t}=4.468, p<0.01)$, NLRP3 $(\mathrm{t}=4.188, p<$ $0.01)$, Aim2 $(\mathrm{t}=5.807, p<0.001)$ and ASC $(\mathrm{t}=4.582, p<0.01)$ compared to NS mice, while JQ1 treatment decreased the levels of NF-KB $(t=4.922, p<0.01)$, NLRP1 $(t=5.732, p<0.001)$, NLRP3 $(t=3.566, p<0.05)$, Aim2 $(\mathrm{t}=5.690, p<0.001)$ and ASC $(\mathrm{t}=3.766, p<0.05)$ compared to those LPS mice. These results suggested that JQ1 treatment could inhibit the activation of NF-KB signaling pathway and NLRP1, NLRP3 and Aim2 inflammasomes induced by LPS injection.

\section{JQ1 treatment ameliorates pyroptosis in the hippocampus of SAE mice exposed to LPS}

Accordingly, a feature of pyroptosis is the pore formation in cell membranes, which could be triggered by gasdermins (GSDMs) family protein [30]. Researches showed that GSDMD [10] and GSDMA [11] were cleaved by Caspase-1/11 upon inflammasome activation and mediated canonical pyroptosis. As displayed in the Real-Time PCR analysis, one-way ANOVA suggested that there were significantly differences among the groups in the mRNA level of Caspase- $1\left(F_{(2,17)}=20.84, p<0.0001\right)$, Caspase-11 $\left(F_{(2,16)}=7.816, p=0.0053\right), \operatorname{GSDMD}\left(\mathrm{F}_{(2,17)}=17.86, p=0.0001\right)$ and $\operatorname{GSDMA}\left(\mathrm{F}_{(2,17)}=20.27, p<0.0001\right)$ (Figure. 3A). Bonferroni post-test analysis revealed that LPS stimulated up-regulation of the mRNA level of Caspase-1 ( $\mathrm{t}=3.994, p<0.01)$, Caspase-11 $(\mathrm{t}=3.590, p<0.01)$, GSDMD $(\mathrm{t}=3.445, p<0.05)$ and GSDMA ( $\mathrm{t}=3.410, p<0.05)$ compared to NS mice, and these effects were effectively attenuated by JQ1 treatment ((Caspase-1 $(\mathrm{t}=6.390, p<0.001)$, Caspase-11 $(\mathrm{t}=3.167, p<0.05), \mathrm{GSDMD}(\mathrm{t}=5.952, p<0.001)$ and GSDMA $(\mathrm{t}=6.361, p<0.001))$. Western blotting further confirmed this fluctuating expression pattern of cleaved Caspase-1, cleaved Caspase-11, GSDMD-N and GSDMA-N. One-way ANOVA revealed that there were significantly differences among the groups in the protein levels of cleaved Caspase-1 $\left(F_{(2,11)}=7.331\right.$, $p=0.0129)$, cleaved Caspase-11 $\left(\mathrm{F}_{(2,11)}=7.146, p=0.0139\right)$, GSDMD-N $\left(\mathrm{F}_{(2,11)}=20.19, p=0.0005\right)$ and GSDMA-N $\left(\mathrm{F}_{(2,11)}=14.74, p=0.0014\right)$ ( Figure.3B and $3 \mathrm{C}$ ). Bonferroni post-test analysis revealed that LPS stimulated up-regulation of the protein level of cleaved Caspase-1 $(\mathrm{t}=2.985, p<0.05)$, cleaved Caspase$11(\mathrm{t}=3.036, p<0.05)$, GSDMD-N $(\mathrm{t}=6.348, p<0.001)$ and GSDMA-N $(\mathrm{t}=3.618, p<0.05)$ compared to NS mice, these effects were effectively attenuated by JQ1 treatment ((cleaved Caspase- $1(t=3.569, p<0.05)$, cleaved Caspase-11 $(\mathrm{t}=3.469, p<0.05)$, GSDMD-N $(\mathrm{t}=3.413, p<0.05)$ and GSDMA-N $(\mathrm{t}=5.316, p<$ $0.01))$. The results indicated JQ1 treatment inhibited LPS-induced the mRNA and protein levels of canonical pyroptosis pathway.

Caspase-8 could cleave GSDMC, and then mediated non-canonical pyroptosis pathway [12]. In order to determine the role of JQ1 treatment on the non-canonical pyroptosis pathway, we examined the 
alterations of mRNA and protein levels of Caspase-8 and GSDMC. The results of Real-Time PCR showed the mRNA level of Caspase-8 $\left(\mathrm{F}_{(2,17)}=0.2848, p=0.7561\right)$ and $\operatorname{GSDMC}\left(\mathrm{F}_{(2,16)}=0.2408, p=0.7892\right)$ had no significant difference among DMSO + NS, DMSO + LPS and JQ1 + LPS group (Figure. 3D). And that western blotting further certificated there were no significant difference among these groups in the protein levels of cleaved Caspase-8 $\left(F_{(2,11)}=0.04195, p=0.9591\right)$ and GSDMC-N $\left(F_{(2,11)}=1.797, p=0.2205\right)$ (Figure. 3E and 3F).

GSDME has been demonstrated to be cleaved by Caspase-3, and then converting apoptosis to pyroptosis [10]. In our present study, we found the mRNA level of Caspase-3 $\left(F_{(2,17)}=0.3112, p=0.7372\right)$ and GSDME $\left(F_{(2,17)}=0.01089, p=0.9892\right)$ (Figure. 3G), and the protein level of cleaved Caspase-3 $\left(F_{(2,11)}=2.405, p=\right.$ $0.1456)$ and GSDME-N $\left(\mathrm{F}_{(2,11)}=0.001761, p=0.9982\right)$ (Figure. $3 \mathrm{H}$ and $\left.3 \mathrm{I}\right)$ had no significantly difference among DMSO + NS, DMSO + LPS and JQ1 + LPS group. Because GSDMB wasn't expressed in mice [31], so we didn't detect the expression of GSDMB. All these results indicated JQ1 treatment inhibited LPSinduced the canonical pyroptosis, but not non-canonical pyroptosis or the apoptosis converting to the pyroptosis.

\section{JQ1 suppresses microglia activity and the release of inflammatory cytokines in the hippocampus of SAE mice exposed to LPS}

Microglia are innate immune cells in the brain, it could be activated after LPS injection [32]. Here, we investigated the role of JQ1 treatment on the activation of microglia. One way ANOVA showed there was significantly difference among the groups in the mRNA level of CD68 $\left(F_{(2,17)}=13.32, p=0.0005\right.$, Figure. 4A ), which was a marker of activated microglia. Bonferroni post-test analysis revealed that LPS stimulated up-regulation of the mRNA level of CD68 $(t=3.469, p<0.05)$, this effect was effectively attenuated by JQ1 treatment $(t=5.045, p<0.001)$. Western blotting further demonstrated that the protein level of CD68 $\left(F_{(2,11)}=7.869, p=0.0106\right.$, Figure. 4B and 4C $)$ was significantly different in DMSO + NS, DMSO + LPS and JQ1 + LPS group. The following post-test analysis revealed that when compared with DMSO + NS mice, LPS stimulation up-regulated the protein level of CD68 $(\mathrm{t}=3.625, p<0.05)$, but JQ1 treatment could reverse the expression of CD68 $(\mathrm{t}=3.209, p<0.05)$. Furthermore, we investigated the expression of IBA1, a marker of activated microglia, by using immunohistochemistry, and the representative images of IBA1-positive cells were shown in Figure. 4D. The results showed that there were significantly differences among the groups in the average optical density (OD) of IBA1 $\left(\mathrm{F}_{(2,46)}=33.89, p<\right.$ 0.0001 , Figure. 4E). Bonferroni post-test analysis revealed that LPS stimulation could increase the expression of IBA1 $(\mathrm{t}=8.011, p<0.001)$, but JQ1 administration could decrease the expression of IBA1 ( $\mathrm{t}$ $=5.582, p<0.001)$. These results indicated that JQ1 could suppress microglia activity induced by LPS injection.

The main inflammatory cytokines that produced by pyroptosis were the IL-1 $\beta$ and IL-18 [33, 34], which could induce the release of downstream inflammatory factors, such as IL-6. And the inflammatory cytokines over-expression has been associated with impairments in hippocampal-dependent memory [35]. Here, we examined alterations in the mRNA expression levels of IL-1 $\beta$, IL-18 and IL- 6 in the 
hippocampus of SAE. One-way ANOVA suggested that there were significantly differences among the groups in the mRNA levels of IL-1 $\beta\left(\mathrm{F}_{(2,16)}=7.729, p=0.0055\right)$, IL-18 $\left(\mathrm{F}_{(2,17)}=16.70, p=0.0002\right)$ and IL-6 $\left(F_{(2,17)}=26.13, p<0.0001\right)$ (Figure. 4F). Bonferroni post-test analysis revealed that expressions of IL-1 $\beta$, IL-18 and IL-6 were significantly increased in DMSO + LPS mice compared with the DMSO + NS mice (IL$1 \beta: t=3.457, p<0.05 ; \mathrm{IL}-18: \mathrm{t}=3.051, p<0.05 ; \mathrm{IL}-6: \mathrm{t}=6.783, p<0.001)$, while JQ1 treatment remarkably decreased the expression of IL-1 $\beta$, IL-18 and IL-6 (IL-1 $\beta: \mathrm{t}=3.455, p<0.05$; IL-18: $\mathrm{t}=5.776, p<0.001$; IL-6:t $=5.556, p<0.001)$. We also examined alterations in the protein levels of IL-1 $\beta$, IL-18 and IL- 6 in the hippocampus of mice. One-way ANOVA revealed that there were significantly differences among the groups in the protein level of IL-1 $\beta\left(\mathrm{F}_{(2,11)}=37.66, p<0.0001\right)$, IL-18 $\left(\mathrm{F}_{(2,11)}=16.86, p=0.0009\right)$ and IL-6 $\left(\mathrm{F}_{(2,11)}=7.486, p=0.0122\right)$ (Figure. $4 \mathrm{G}$ and $4 \mathrm{H}$ ). Bonferroni post-test analysis revealed that LPS stimulated up-regulation of the protein level of IL-1 $\beta(t=3.315, p<0.05)$, IL-18 $(t=3.614, p<0.05)$ and IL-6 $(t=2.978$, $p<0.05)$ compared to NS mice, while JQ1 treatment remarkably decreased expression of IL-1 $\beta$, IL-18 and IL-6 (IL-1 $\beta: \mathrm{t}=8.603, p<0.01 ; \mathrm{IL}-18: \mathrm{t}=5.743, p<0.001 ; \mathrm{IL}-6: \mathrm{t}=3.629, p<0.05)$. These results suggested JQ1 treatment inhibited the upregulated expression of IL-1 $\beta$, IL-18 and IL- 6 induced by LPS.

\section{JQ1 prevents tight junction and reverses neuronal morphological damage in the hippocampus of SAE mice exposed to LPS}

Hippocampus is one of the important region of blood-brain barrier, high dose of LPS could damage the blood brain barrier (BBB) [36]. In our current study, tight junction proteins occludin and ZO-1 were detected to assess the effect of JQ1 on the blood-brain barrier of hippocampus. And the results showed that there were significantly differences among the groups in the protein level of occludin $\left(\mathrm{F}_{(2,11)}=24.41, p=\right.$ $0.0002)$ and ZO-1 $\left(F_{(2,11)}=35.03, p<0.0001\right)$ (Figure. 5A and 5B). Bonferroni post-test analysis revealed that LPS stimulated down-regulation of the protein level of occludin $(t=5.776, p<0.001)$ and ZO-1 $(\mathrm{t}=$ $4.964, p<0.01)$ compared to NS mice, while JQ1 treatment remarkably increased the expression of occludin $(\mathrm{t}=6.293, p<0.001)$ and ZO-1 $(\mathrm{t}=8.319, p<0.001)$.

To determine whether neurons were the main cell type that participated in LPS-induced pyroptosis. Western blotting was used to assess the relative expression of the NeuN protein, which is a marker of neuron, and one-way ANOVA revealed that there were significantly differences among the groups in the protein level of NeuN $\left(F_{(2,11)}=11.89, p=0.003\right)$ (Figure. 5A and 5B). Bonferroni post-test analysis revealed that LPS stimulated down-regulation of the protein level of NeuN $(t=4.674, p<0.01)$ compared to NS mice, while JQ1 treatment remarkably increased the expression of NeuN $(t=3.540, p<0.05)$. Furthermore, we used immunohistochemistry to estimate the expression of $\mathrm{NeuN}$, and the newborn neurons maker, Doublecortin (DCX). The representative images of NeuN and DCX-positive cells are shown in Figure. 5C. The results showed that there were significantly differences among the average optical density (OD) of NeuN $\left(\mathrm{F}_{(2,22)}=47.81, p<0.0001\right)$ and $\mathrm{DCX}\left(\mathrm{F}_{(2,50)}=34.48, p<0.0001\right)$ (Figure. 5D). Bonferroni post-test analysis revealed that LPS stimulated could increase the expression of $\mathrm{NeuN}(\mathrm{t}=$ $6.443, p<0.001)$ and $\mathrm{DCX}(\mathrm{t}=6.540, p<0.001)$, but JQ1 administration could decrease the expression of $\operatorname{NeuN}(\mathrm{t}=9.659, p<0.001)$ and DCX $(\mathrm{t}=7.606, p<0.001)$. These results suggested that JQ1 
administration could enhance tight junction of hippocampus and inhibit neuronal death, as well as protect neurogenesis.

\section{Discussion}

In the present study, we showed that LPS enhanced hippocampal BRD4 and p-BRD4, and upregulated NFKB-dependent NLRP1, NLRP3 and Aim2 inflammasomes expression, which finally triggered neuronal damage in a canonical pyroptotic manner and promoted the release of inflammatory factors.

Pretreatment with BRD4 inhibitor JQ1 remarkably suppressed the expression of NLRP1, NLRP3 and Aim2 inflammasomes, then inhibited canonical pyroptotic signaling pathway, which mediated by cleaved Caspase-1/11 and GSDMD, GSMDA, and the associated release of the inflammatory cytokines IL-1 $\beta$, IL18 and IL-6 also decreased in the hippocampus of mice. Moreover, JQ1 protected mice from LPS-induced hippocampal microglial activation, tight junction injury of BBB and neuronal damage. These supports the hypothesis that JQ1 inhibits the activation of inflammasomes, alleviates pyroptosis and inflammation, protects BBB and neuronal, and thus protects mice from SAE.

Sepsis, characterized as life-threatening organ dysfunction caused by a dysregulated host response to infection [37], remains a major challenge in medicine with high mortality rates [38, 39]. In response to infection, the activation of inflammasomes becomes an important mediator of pyroptosis, i.e. NLRP3/Caspase-1-mediated pyroptosis [3]. The hippocampus appears to be vulnerable since sepsis survivors develop pronounced hippocampal atrophy [40]. And it has been showed that pyroptosis occurs in the hippocampus of sepsis-induced brain injury [41], but its mechanism and treatment scheme is still to be evaluated.

Increasing studies indicate that BRD4 might be a promising therapeutic target in multiple diseases associated with inflammatory response, such as osteoarthritis [42], rheumatoid arthritis [43] and spinal cord injury [44]. Currently, it is still unclear whether and how BRD4 or p-BRD4 is involved in pyroptosis after SAE induced by LPS, a widely accepted model of endotoxin-mediated inflammation [45]. LPS injected by intraperitoneal could damage blood-brain barrier [46] and then induced SAE [47]. Herein, we first determined that BRD4 and p-BRD4 were up-regulated in the hippocampus of SAE mice induced by LPS injection, which were both reduced by JQ1 treatment. However, whether p-BRD4 is directly related to SAE needs further study. Our study also demonstrated that JQ1 treatment could inhibit weight loss and splenomegaly, and decrease the release of serum PCT and D-LDH following LPS injection to resist sepsis. In addition, the inhibition of BRD4 by its small molecule inhibitor JQ1 could block BBB disruption as manifested by enhancing the expression of tight junction proteins (occludin and ZO-1). To explore whether neuronal damage existed in SAE, we observed the expression of NeuN and DCX in the brains of SAE mice. The results showed that the numbers of both mature neurons and newborn neurons were significantly decreased in the SAE mice compared with control mice, and JQ1 intervention could obviously reverse these changes, indicating JQ1 could protect BBB and inhibit neuronal damage induced by LPS. 
The cleavage of GSDMs by inflammasome-activated caspases are critical step in inducing pyroptosis, and the $\mathrm{N}$-terminal domain of GSDMs (GSDMs-N) is commonly recognized as an executor of pyroptosis [48]. In the present study, we explored the mechanism how JQ1 inhibited neuronal damage in SAE. And the results showed that the levels of GSDMD-N and GSDMA-N, which were cleaved by Caspase-1/11, were increased in the brain of SAE mice. While the expression of GSDMC-N and GSDME-N, which were cleaved by Caspase-8 or Caspase3, had no obvious change. These results indicated that SAE could induce neuronal pyroptosis by a canonical manner. Furthermore, the role of BRD4 in neuronal pyroptosis of SAE was further clarified by the BRD4 inhibitor JQ1. Data in our study demonstrated that JQ1 administration could increase the amount of neuron and meanwhile decrease the expression of GSDMDN, GSDMA-N and cleaved Caspase-1/11, which suggested that JQ1 could protect neuron from LPSinduced damage through inhibiting neuronal pyroptosis.

Pyroptosis is suggested to be inflammasome-dependent. Herein, we investigated the effects of JQ1 on the NLRP1, NLRP3 and Aim2 inflammasomes, and found that the expression of NLRP1, NLRP3, Aim2 and ASC was significantly increased in the hippocampus of SAE, while these effects were effectively attenuated by JQ1 treatment. These results indicated JQ1 inhibited neuronal pyroptosis dependent on the NLRP1, NLRP3, Aim2 inflammasomes. The transcription factor NF-KB plays a key role in activating the inflammasome signaling pathway [49], and BRD4 is an important transcriptional regulator of NF-KB [50]. We further determined the expression of NF-KB in SAE. We found that JQ1 treatment could effectively down-regulate the expression of hippocampal NF-KB. Microglia could also be activated after LPS injection [32], and a series of inflammatory cytokines such as IL-1 $\beta$ and IL-18, which were produced during pyroptosis process, were also released by LPS stimulation [33, 34]. Reduced expression of microglia markers (CD68 and IBA1) demonstrated that JQ1 treatment alleviated LPS-induced microglia activation. Additionally, the expression of IL-1 $\beta$, IL-18 and the downstream inflammatory factor IL- 6 were increased after LPS injection, while JQ1 administration could reverse their high expression, indicating JQ1 could alleviate neuroinflammation in the hippocampus of SAE mice. Thus, we considered that BRD4 mediated NF-KB activation to initiate the NLRP1, NLRP3 and Aim2 inflammasomes signaling pathway, resulting in pyroptosis, which might be involved in the pathogenic process of SEA.

\section{Conclusion}

In conclusion, our results demonstrated that JQ1 could reduce severity of SAE through partial abrogation of neuroinflammation-related pathogenic mechanisms, and JQ1 could be put forward as an ancillary beneficial agent in combination with available drug treatments to slow down SAE pathogenic process and occurrence rate of its clinical signs.

\section{Declarations}

Acknowledgments Not applicable. 
Author Contributions Xiao Lin Zhong and Zuyao Chen performed PCR and Western Blotting tests, Yajuan Wang and Mingli Mao performed ELISA and Immunohistochemistry tests, Yingcheng Deng, Mengmeng Shi, Yang Xu established the animal model and given JQ1 intervention. Ling Chen performed statistical analysis. Xiao Lin Zhong and Wenyu Cao drafted the manuscript. Xiao Lin Zhong, Ling Chen and Wenyu Cao performed research design and manuscript revision.

Funding Information Support provided by research grants from the National Natural Science Foundation of China (81901147), the Natural Science Foundation of Hunan Province ( 2019JJ50541, 2019JJ50545).

Availability of data and materials Not applicable.

\section{Compliance with Ethical Standards}

Conflict of Interest The authors declare that they have no conflict of interest.

Ethics Approval The experimental protocol was approved by the Animal Care and Use Committee of the University of South China and conformed to the National Institutes of Health Guide for the Care and Use of Laboratory Animals.

Consent for Participate Not applicable.

Consent for Publication Not applicable.

Code Availability Not applicable.

\section{References}

1. Gofton TE, Young GB (2012) Sepsis-associated encephalopathy. Nature reviews Neurology 8(10):557-566. doi:10.1038/nrneurol.2012.183

2. Xu XE, Liu L, Wang YC, Wang CT, Zheng Q, Liu QX, Li ZF, Bai XJ, Liu XH (2019) Caspase-1 inhibitor exerts brain-protective effects against sepsis-associated encephalopathy and cognitive impairments in a mouse model of sepsis. Brain Behav Immun 80:859-870. doi:10.1016/j.bbi.2019.05.038

3. Fu Q, Wu J, Zhou XY, Ji MH, Mao QH, Li Q, Zong MM, Zhou ZQ, Yang JJ (2019) NLRP3/Caspase-1 Pathway-Induced Pyroptosis Mediated Cognitive Deficits in a Mouse Model of Sepsis-Associated Encephalopathy. Inflammation 42(1):306-318. doi:10.1007/s10753-018-0894-4

4. Widmann CN, Heneka MT (2014) Long-term cerebral consequences of sepsis. Lancet Neurol 13(6):630-636. doi:10.1016/S1474-4422(14)70017-1

5. Orning P, Lien E, Fitzgerald KA (2019) Gasdermins and their role in immunity and inflammation. The Journal of experimental medicine 216(11):2453-2465. doi:10.1084/jem.20190545

6. Dempsey C, Rubio Araiz A, Bryson KJ, Finucane O, Larkin C, Mills EL, Robertson AAB, Cooper MA, O'Neill LAJ, Lynch MA (2017) Inhibiting the NLRP3 inflammasome with MCC950 promotes non- 
phlogistic clearance of amyloid-beta and cognitive function in APP/PS1 mice. Brain Behav Immun 61:306-316. doi:10.1016/j.bbi.2016.12.014

7. Fan Y, Du L, Fu Q, Zhou Z, Zhang J, Li G, Wu J (2018) Inhibiting the NLRP3 Inflammasome With MCC950 Ameliorates Isoflurane-Induced Pyroptosis and Cognitive Impairment in Aged Mice. Frontiers in cellular neuroscience 12:426. doi:10.3389/fncel.2018.00426

8. Boise LH, Collins CM (2001) Salmonella-induced cell death: apoptosis, necrosis or programmed cell death? Trends in microbiology 9(2):64-67. doi:10.1016/s0966-842x(00)01937-5

9. Rogers C, Erkes DA, Nardone A, Aplin AE, Fernandes-Alnemri T, Alnemri ES (2019) Gasdermin pores permeabilize mitochondria to augment caspase-3 activation during apoptosis and inflammasome activation. Nature communications 10(1):1689. doi:10.1038/s41467-019-09397-2

10. Zhou Z, He H, Wang K, Shi X, Wang Y, Su Y, Wang Y, Li D, Liu W, Zhang Y, Shen L, Han W, Shen L, Ding J, Shao F (2020) Granzyme A from cytotoxic lymphocytes cleaves GSDMB to trigger pyroptosis in target cells. Science 368 (6494). doi:10.1126/science.aaz7548

11. Ding J, Wang K, Liu W, She Y, Sun Q, Shi J, Sun H, Wang DC, Shao F (2016) Pore-forming activity and structural autoinhibition of the gasdermin family. Nature 535(7610):111-116.

doi:10.1038/nature18590

12. Hou J, Zhao R, Xia W, Chang CW, You Y, Hsu JM, Nie L, Chen Y, Wang YC, Liu C, Wang WJ, Wu Y, Ke B, Hsu JL, Huang K, Ye Z, Yang Y, Xia X, Li Y, Li CW, Shao B, Tainer JA, Hung MC (2020) PD-L1-mediated gasdermin $C$ expression switches apoptosis to pyroptosis in cancer cells and facilitates tumour necrosis. Nat Cell Biol 22(10):1264-1275. doi:10.1038/s41556-020-0575-z

13. Ge X, Li W, Huang S, Yin Z, Xu X, Chen F, Kong X, Wang H, Zhang J, Lei P (2018) The pathological role of NLRs and AIM2 inflammasome-mediated pyroptosis in damaged blood-brain barrier after traumatic brain injury. Brain research 1697:10-20. doi:10.1016/j.brainres.2018.06.008

14. McKenzie BA, Mamik MK, Saito LB, Boghozian R, Monaco MC, Major EO, Lu JQ, Branton WG, Power C (2018) Caspase-1 inhibition prevents glial inflammasome activation and pyroptosis in models of multiple sclerosis. Proc Natl Acad Sci USA 115(26):E6065-E6074. doi:10.1073/pnas.1722041115

15. Yap JKY, Pickard BS, Chan EWL, Gan SY (2019) The Role of Neuronal NLRP1 Inflammasome in Alzheimer's Disease: Bringing Neurons into the Neuroinflammation Game. Mol Neurobiol 56(11):7741-7753. doi:10.1007/s12035-019-1638-7

16. Gao C, Yan Y, Chen G, Wang T, Luo C, Zhang M, Chen X, Tao L (2020) Autophagy Activation Represses Pyroptosis through the IL-13 and JAK1/STAT1 Pathways in a Mouse Model of Moderate Traumatic Brain Injury. ACS Chem Neurosci 11(24):4231-4239.

doi:10.1021/acschemneuro.0c00517

17. Liu W, Chen Y, Meng J, Wu M, Bi F, Chang C, Li H, Zhang L (2018) Ablation of caspase-1 protects against TBI-induced pyroptosis in vitro and in vivo. J Neuroinflamm 15(1):48. doi:10.1186/s12974018-1083-y

18. Brown JD, Lin CY, Duan Q, Griffin G, Federation A, Paranal RM, Bair S, Newton G, Lichtman A, Kung A, Yang T, Wang H, Luscinskas FW, Croce K, Bradner JE, Plutzky J (2014) NF-kappaB directs dynamic 
super enhancer formation in inflammation and atherogenesis. Molecular cell 56(2):219-231. doi:10.1016/j.molcel.2014.08.024

19. Chen J, Wang Z, Hu X, Chen R, Romero-Gallo J, Peek RM Jr, Chen LF (2016) BET Inhibition Attenuates Helicobacter pylori-Induced Inflammatory Response by Suppressing Inflammatory Gene Transcription and Enhancer Activation. Journal of immunology 196(10):4132-4142. doi:10.4049/jimmunol.1502261

20. Nicodeme E, Jeffrey KL, Schaefer U, Beinke S, Dewell S, Chung CW, Chandwani R, Marazzi I, Wilson P, Coste H, White J, Kirilovsky J, Rice CM, Lora JM, Prinjha RK, Lee K, Tarakhovsky A (2010) Suppression of inflammation by a synthetic histone mimic. Nature 468(7327):1119-1123. doi:10.1038/nature09589

21. Zou Z, Huang B, Wu X, Zhang H, Qi J, Bradner J, Nair S, Chen LF (2014) Brd4 maintains constitutively active NF-kappaB in cancer cells by binding to acetylated RelA. Oncogene 33(18):2395-2404. doi:10.1038/onc.2013.179

22. Bao Y, Wu X, Chen J, Hu X, Zeng F, Cheng J, Jin H, Lin X, Chen LF (2017) Brd4 modulates the innate immune response through Mnk2-elF4E pathway-dependent translational control of IkappaBalpha. Proc Natl Acad Sci USA 114(20):E3993-E4001. doi:10.1073/pnas.1700109114

23. Wu SY, Nin DS, Lee AY, Simanski S, Kodadek T, Chiang CM (2016) BRD4 Phosphorylation Regulates HPV E2-Mediated Viral Transcription, Origin Replication, and Cellular MMP-9 Expression. Cell reports 16(6):1733-1748. doi:10.1016/j.celrep.2016.07.001

24. Guo W, Long H, Bu Q, Zhao Y, Wang H, Tian J, Cen X (2020) Role of BRD4 phosphorylation in the nucleus accumbens in relapse to cocaine-seeking behavior in mice. Addiction biology 25(5):e12808. doi:10.1111/adb. 12808

25. Wang M, Liu M, Zhang J, Liu J, Ye J, Xu Y, Wang Z, Ye D, Zhao M, Wan J (2020) Resolvin D1 protects against sepsis-induced cardiac injury in mice. BioFactors 46(5):766-776. doi:10.1002/biof.1668

26. Wu F, Chen X, Zhai L, Wang H, Sun M, Song C, Wang T, Qian Z (2020) CXCR2 antagonist attenuates neutrophil transmigration into brain in a murine model of LPS induced neuroinflammation. Biochem Biophys Res Commun 529(3):839-845. doi:10.1016/j.bbrc.2020.05.124

27. Zhong X, Cao W, Zhao H, Chen L, Cao J, Wei L, Tang Y, Zhong J, Xiao X, Zu X, Liu J (2020) MicroRNA32-5p knockout eliminates lipopolysaccharide-induced depressive-like behavior in mice through inhibition of astrocyte overactivity. Brain Behav Immun 84:10-22. doi:10.1016/j.bbi.2019.11.001

28. Takeuchi O, Akira S (2010) Pattern recognition receptors and inflammation. Cell 140(6):805-820. doi:10.1016/j.cell.2010.01.022

29. Zhang X, Guan Z, Wang X, Sun D, Wang D, Li Y, Pei B, Ye M, Xu J, Yue X (2020) Curcumin Alleviates Oxaliplatin-Induced Peripheral Neuropathic Pain through Inhibiting Oxidative Stress-Mediated Activation of NF-kappaB and Mitigating Inflammation. Biol Pharm Bull 43(2):348-355. doi:10.1248/bpb.b19-00862

30. Wree A, Eguchi A, McGeough MD, Pena CA, Johnson CD, Canbay A, Hoffman HM, Feldstein AE (2014) NLRP3 inflammasome activation results in hepatocyte pyroptosis, liver inflammation, and fibrosis in 
mice. Hepatology 59(3):898-910. doi:10.1002/hep.26592

31. Das S, Miller M, Beppu AK, Mueller J, McGeough MD, Vuong C, Karta MR, Rosenthal P, Chouiali F, Doherty TA, Kurten RC, Hamid Q, Hoffman HM, Broide DH (2016) GSDMB induces an asthma phenotype characterized by increased airway responsiveness and remodeling without lung inflammation. Proc Natl Acad Sci USA 113(46):13132-13137. doi:10.1073/pnas.1610433113

32. Gu E, Pan W, Chen K, Zheng Z, Chen G, Cai P (2021) LncRNA H19 Regulates Lipopolysaccharide (LPS)-Induced Apoptosis and Inflammation of BV2 Microglia Cells Through Targeting miR-3253p/NEUROD4 Axis. Journal of molecular neuroscience: MN 71(6):1256-1265. doi:10.1007/s12031020-01751-0

33. Kayagaki N, Stowe IB, Lee BL, O'Rourke K, Anderson K, Warming S, Cuellar T, Haley B, Roose-Girma M, Phung QT, Liu PS, Lill JR, Li H, Wu J, Kummerfeld S, Zhang J, Lee WP, Snipas SJ, Salvesen GS, Morris LX, Fitzgerald L, Zhang Y, Bertram EM, Goodnow CC, Dixit VM (2015) Caspase-11 cleaves gasdermin $D$ for non-canonical inflammasome signalling. Nature 526(7575):666-671. doi:10.1038/nature15541

34. Shi FD (2015) Neuroinflammation. Neuroscience bulletin 31 (6):714-716. doi:10.1007/s12264-0151568-y

35. Rojas-Colon LA, Dash PK, Morales-Vias FA, Lebron-Davila M, Ferchmin PA, Redell JB, MaldonadoMartinez G, Velez-Torres WI (2021) 4R-cembranoid confers neuroprotection against LPS-induced hippocampal inflammation in mice. J Neuroinflamm 18(1):95. doi:10.1186/s12974-021-02136-9

36. Banks WA, Gray AM, Erickson MA, Salameh TS, Damodarasamy M, Sheibani N, Meabon JS, Wing EE, Morofuji Y, Cook DG, Reed MJ (2015) Lipopolysaccharide-induced blood-brain barrier disruption: roles of cyclooxygenase, oxidative stress, neuroinflammation, and elements of the neurovascular unit. J Neuroinflamm 12:223. doi:10.1186/s12974-015-0434-1

37. Verdonk F, Blet A, Mebazaa A (2017) The new sepsis definition: limitations and contribution to research and diagnosis of sepsis. Curr Opin Anaesthesiol 30(2):200-204. doi:10.1097/ACO.0000000000000446

38. Engel C, Brunkhorst FM, Bone HG, Brunkhorst R, Gerlach H, Grond S, Gruendling M, Huhle G, Jaschinski U, John S, Mayer K, Oppert M, Olthoff D, Quintel M, Ragaller M, Rossaint R, Stuber F, Weiler N, Welte T, Bogatsch H, Hartog C, Loeffler M, Reinhart K (2007) Epidemiology of sepsis in Germany: results from a national prospective multicenter study. Intensive care medicine 33(4):606-618. doi:10.1007/s00134-006-0517-7

39. Gaieski DF, Edwards JM, Kallan MJ, Carr BG (2013) Benchmarking the incidence and mortality of severe sepsis in the United States. Critical care medicine 41(5):1167-1174. doi:10.1097/CCM.0b013e31827c09f8

40. Bluemel P, Wickel J, Grunewald B, Ceanga M, Keiner S, Witte OW, Redecker C, Geis C, Kunze A (2021) Sepsis promotes gliogenesis and depletes the pool of radial glia like stem cells in the hippocampus. Exp Neurol 338:113591. doi:10.1016/j.expneurol.2020.113591 
41. Zhou R, Yang X, Li X, Qu Y, Huang Q, Sun X, Mu D (2019) Recombinant CC16 inhibits NLRP3/caspase-1-induced pyroptosis through p38 MAPK and ERK signaling pathways in the brain of a neonatal rat model with sepsis. J Neuroinflamm 16(1):239. doi:10.1186/s12974-019-1651-9

42. Jiang Y, Zhu L, Zhang T, Lu H, Wang C, Xue B, Xu X, Liu Y, Cai Z, Sang W, Hua Y, Ma J (2017) BRD4 has dual effects on the HMGB1 and NF-kappaB signalling pathways and is a potential therapeutic target for osteoarthritis. Biochimica et biophysica acta Molecular basis of disease 1863(12):30013015. doi:10.1016/j.bbadis.2017.08.009

43. Xiao Y, Liang L, Huang M, Qiu Q, Zeng S, Shi M, Zou Y, Ye Y, Yang X, Xu H (2016) Bromodomain and extra-terminal domain bromodomain inhibition prevents synovial inflammation via blocking IkappaB kinase-dependent NF-kappaB activation in rheumatoid fibroblast-like synoviocytes. Rheumatology 55(1):173-184. doi:10.1093/rheumatology/kev312

44. Wang J, Chen J, Jin H, Lin D, Chen Y, Chen X, Wang B, Hu S, Wu Y, Wu Y, Zhou Y, Tian N, Gao W, Wang $X$, Zhang $X$ (2019) BRD4 inhibition attenuates inflammatory response in microglia and facilitates recovery after spinal cord injury in rats. J Cell Mol Med 23(5):3214-3223. doi:10.1111/jcmm.14196

45. Luo RY, Luo C, Zhong F, Shen WY, Li H, Hu ZL, Dai RP (2020) ProBDNF promotes sepsis-associated encephalopathy in mice by dampening the immune activity of meningeal CD4(+) T cells. J Neuroinflamm 17(1):169. doi:10.1186/s12974-020-01850-0

46. Liu Y, Wang L, Du N, Yin X, Shao H, Yang L (2021) Ramelteon Ameliorates LPS-Induced Hyperpermeability of the Blood-Brain Barrier (BBB) by Activating Nrf2. Inflammation. doi:10.1007/s10753-021-01451-w

47. Kikuchi DS, Campos ACP, Qu H, Forrester SJ, Pagano RL, Lassegue B, Sadikot RT, Griendling KK, Hernandes MS (2019) Poldip2 mediates blood-brain barrier disruption in a model of sepsisassociated encephalopathy. J Neuroinflamm 16(1):241. doi:10.1186/s12974-019-1575-4

48. Kuang S, Zheng J, Yang H, Li S, Duan S, Shen Y, Ji C, Gan J, Xu XW, Li J (2017) Structure insight of GSDMD reveals the basis of GSDMD autoinhibition in cell pyroptosis. Proc Natl Acad Sci USA 114(40):10642-10647. doi:10.1073/pnas.1708194114

49. Afonina IS, Zhong Z, Karin M, Beyaert R (2017) Limiting inflammation-the negative regulation of NFkappaB and the NLRP3 inflammasome. Nature immunology 18(8):861-869. doi:10.1038/ni.3772

50. Huang B, Yang XD, Zhou MM, Ozato K, Chen LF (2009) Brd4 coactivates transcriptional activation of NF-kappaB via specific binding to acetylated RelA. Molecular cellular biology 29(5):1375-1387. doi:10.1128/MCB.01365-08

\section{Figures}


A

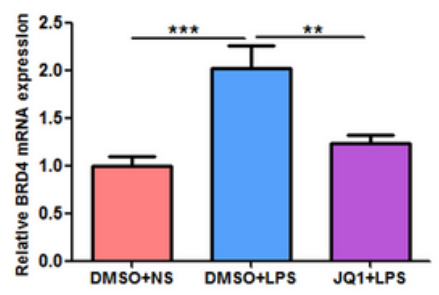

D

DMSO+NS

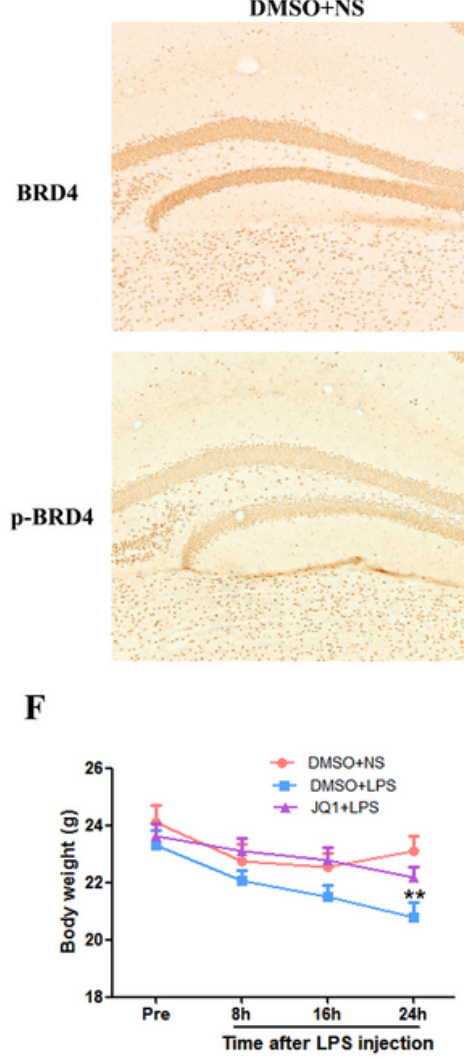

B

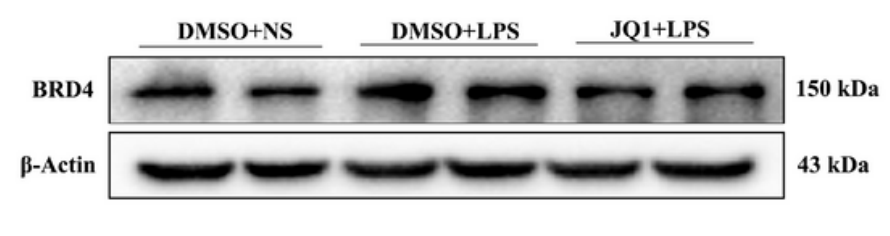

DMSO+LPS
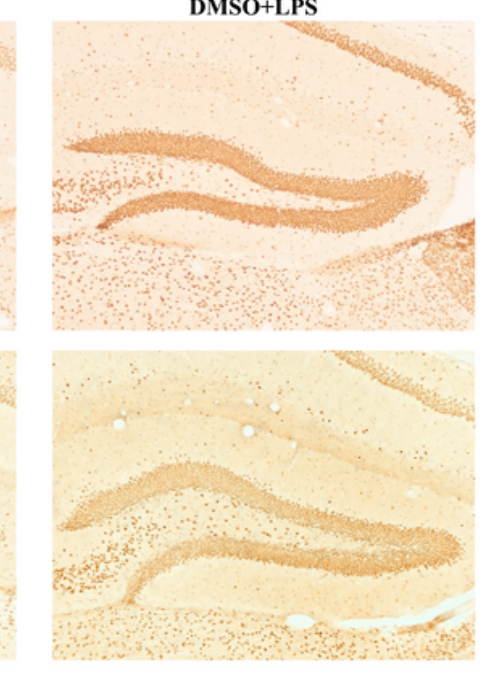

G

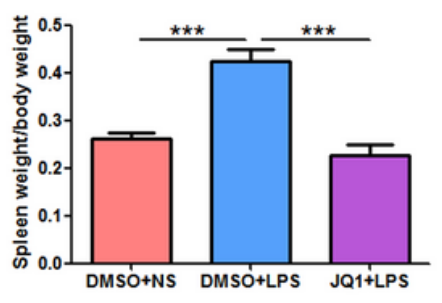

C

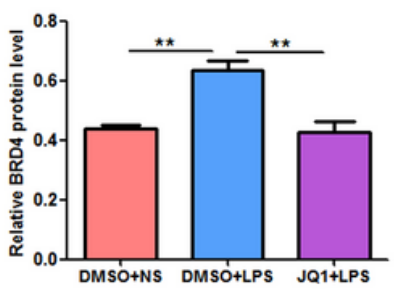

E
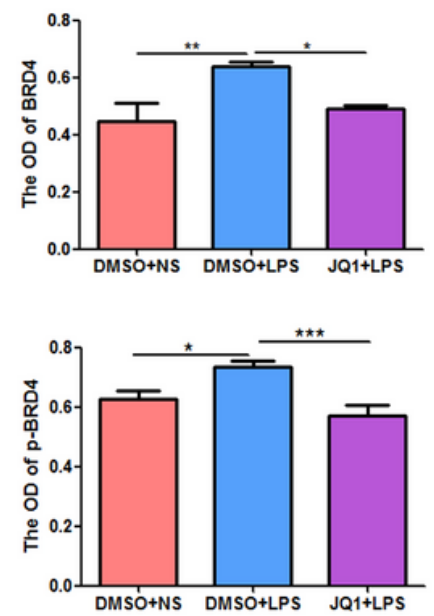

I
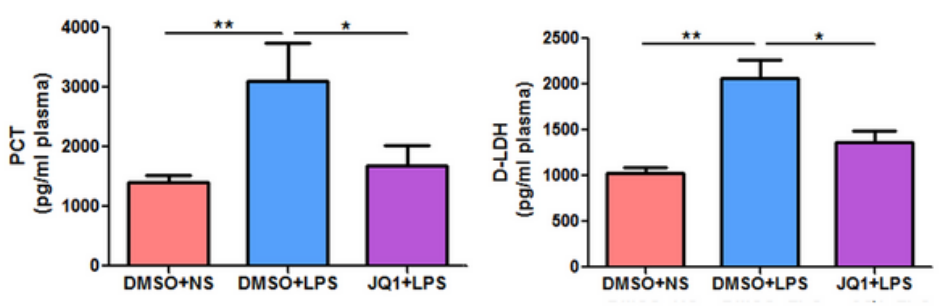

Figure 1

The effect of JQ1 on the expression of BRD4 and its phosphorylation and on the sepsis-related symptoms induced by LPS injection. (A) Representative the mRNA expression level of BRD4. (B) Representative western blotting immunolabeling of BRD4 in the hippocampus and (C) semiquantitative analysis of BRD4 protein relative to $\beta$-Actin. (D) Representative immunohistochemistry images of BRD4 and p-BRD4-positive cells and (E) Quantitative analysis of the average optical density (OD) of BRD4 and p-BRD4 in hippocampus for each group. (F) The body weight of mice in pre, $8 \mathrm{~h}, 16 \mathrm{~h}$ and $24 \mathrm{~h}$ after LPS stimulation. (G) The spleen weight/body weight of mice $24 \mathrm{~h}$ after LPS injection. (H and I) The level of serum Procalcitonin (PCT) and D-lactate dehydrogenase by using ELISA kits. Bar=100 $\mu$ m. $p<0.05$ was considered significant, ${ }^{*} p<0.05,{ }^{*} p<0.01$ and ${ }^{* * *} p<0.001$. The results are shown as the mean $\pm S E M ; n=4-$ 8 animals in each experimental group. 
A

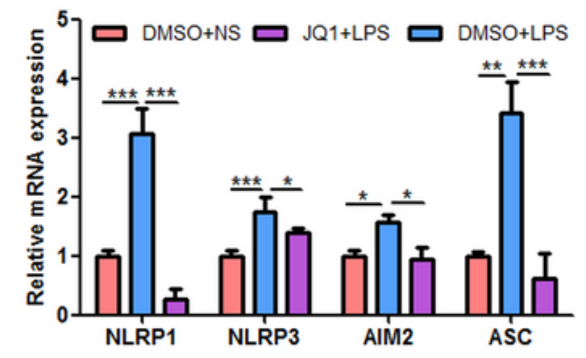

B

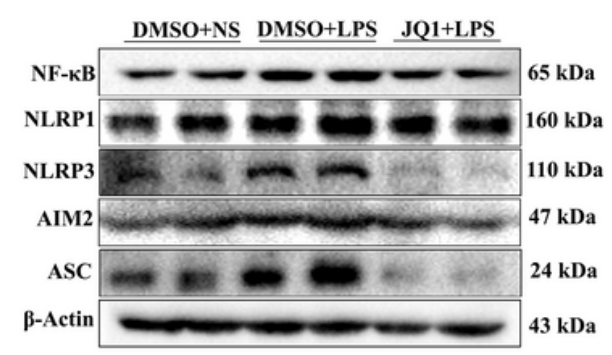

C

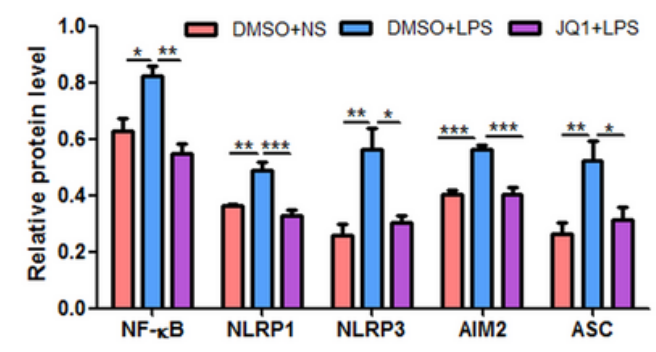

\section{Figure 2}

The effect of JQ1 on the expressions of the NF-KB and inflammasomes in the hippocampus induced by LPS injection. (A) Representative the mRNA expression levels of NLRP1, NLRP3, Aim2 and ASC. (B) Representative western blot immunolabeling of NF-kB, NLRP1, NLRP3, Aim2 and ASC and (C) semiquantitative analysis of NF-kB, NLRP1, NLRP3, Aim2 and ASC protein relative to $\beta$-Actin. $p<0.05$ was considered significant, ${ }^{*} p<0.05$, ${ }^{*} \mathrm{p}<0.01$ and ${ }^{* \star \star} p<0.001$. The results are shown as the mean $\pm S E M ; n=4$ 8 animals in each experimental group.

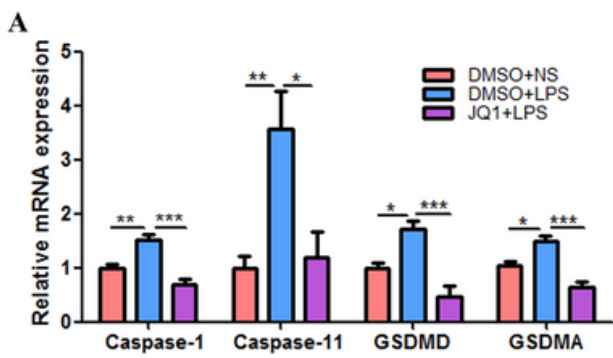

B

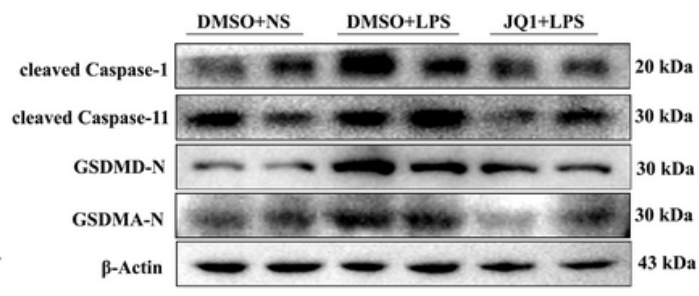

$\mathbf{E}$

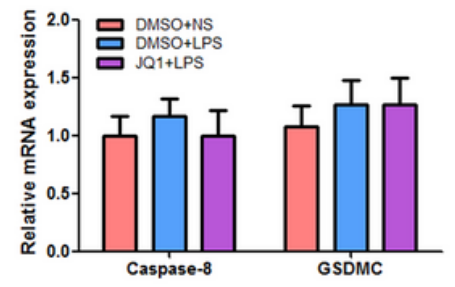

G

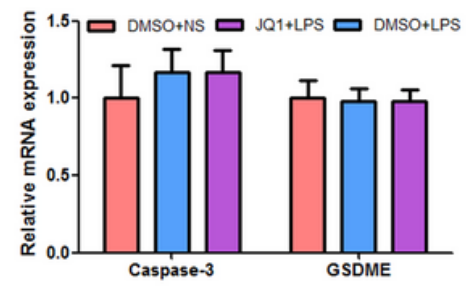

C
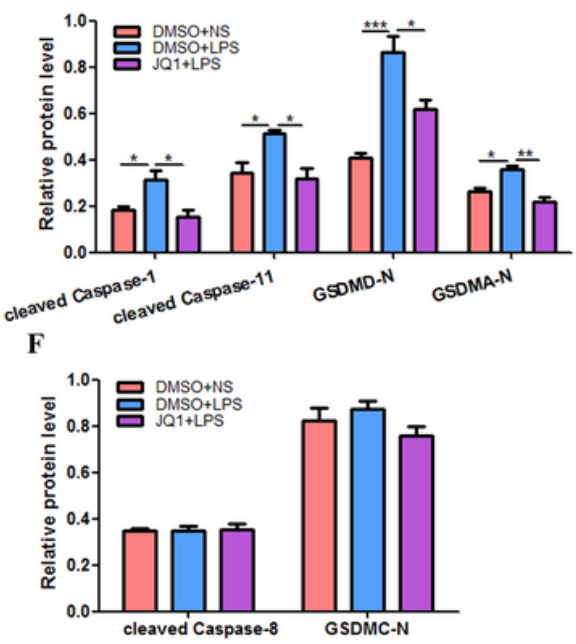

I

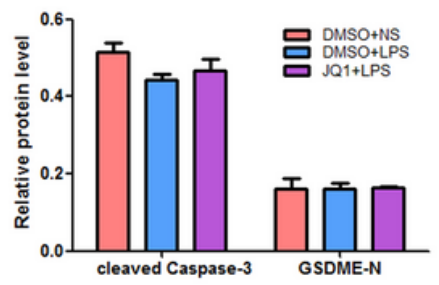

Figure 3

The effect of JQ1 on the expression of gasdermin family protein in the hippocampus induced by LPS injection. (A) Representative the mRNA expression levels of Caspase-1, Caspase-11, GSDMD and GSDMA. (B) Representative western blot immunolabeling of cleaved Caspase-1, cleaved Caspase-11, GSDMD-N and GSDMA-N and (C) semiquantitative analysis of cleaved Caspase-1, cleaved Caspase-11, GSDMD-N 
and GSDMA-N protein relative to $\beta$-Actin. (D) Representative the mRNA expression levels of Caspase-8 and GSDMC. (E) Representative western blotting immunolabeling of cleaved Caspase-8 and GSDMC-N and $(F)$ semiquantitative analysis of cleaved Caspase-8 and GSDMC-N protein relative to $\beta$-Actin. (G) Representative the mRNA expression levels of Caspase-3 and GSDME. $(\mathrm{H})$ Representative western blot immunolabeling of cleaved Caspase-3 and GSDME-N and (I) semiquantitative analysis of cleaved Caspase-3 and GSDME-N protein relative to $\beta$-Actin. $p<0.05$ was considered significant, ${ }^{*} p<0.05,{ }^{*} p<0.01$ and ${ }^{* \star} p<0.001$. The results are shown as the mean $\pm S E M ; n=4-8$ animals in each experimental group.

A

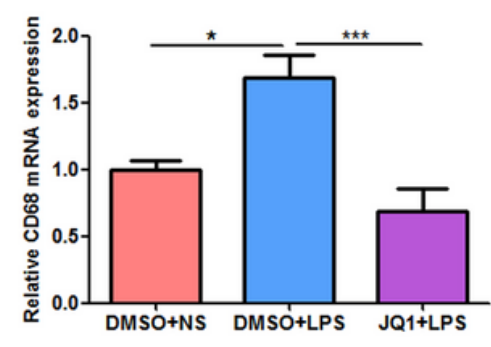

D

DMSO+NS

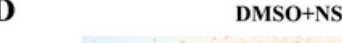

IBA1
B

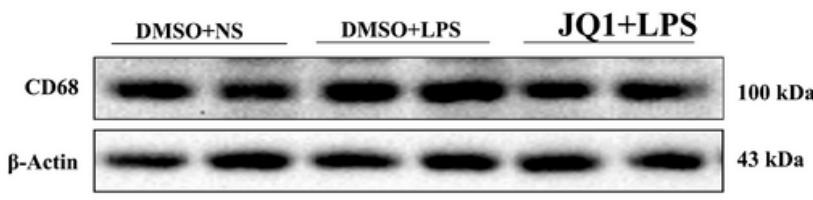

DMSO+LPS
JQ1+LPS

C

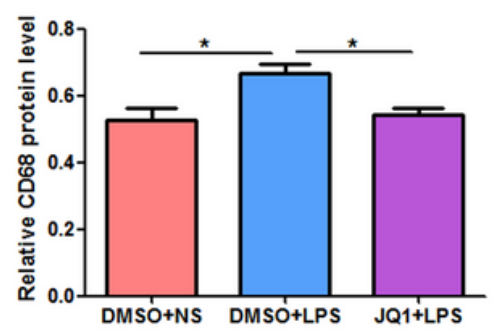

$\mathbf{E}$

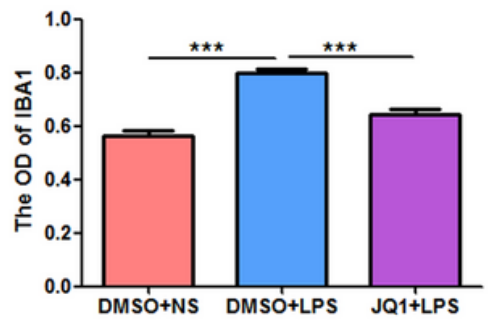

$\mathbf{H}$

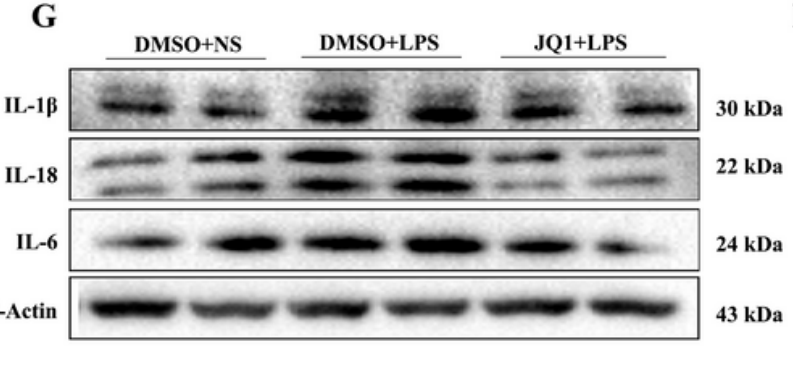

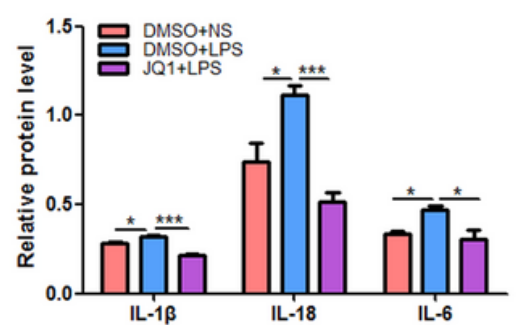

Figure 4

The effect of JQ1 on the activation of microglia and the upregulated expression of inflammatory factors in the hippocampus induced by LPS injection. (A) Representative the mRNA levels of CD68. (B) Representative western blotting immunolabeling of CD68 and (C) semiquantitative analysis of CD68 protein relative to $\beta$-Actin. (D) Representative immunohistochemistry images of IBA1 positive cells and (E) quantitative analysis of the average optical density (OD) of IBA1 in hippocampus for each group. (F) Representative the mRNA levels of IL-1 $\beta$, IL-18 and IL-6. (G) Representative western blotting immunolabeling of IL-1 $\beta$, IL-18 and IL- 6 and $(H)$ semiquantitative analysis of IL-1 $\beta$, IL-18 and IL- 6 protein relative to $\beta$-Actin. Bar $=100 \mu \mathrm{m}$. $p<0.05$ was considered significant, ${ }^{*} p<0.05$ and ${ }^{* \star *} p<0.001$. The results are shown as the mean $\pm S E M ; n=4-8$ animals in each experimental group. 
A

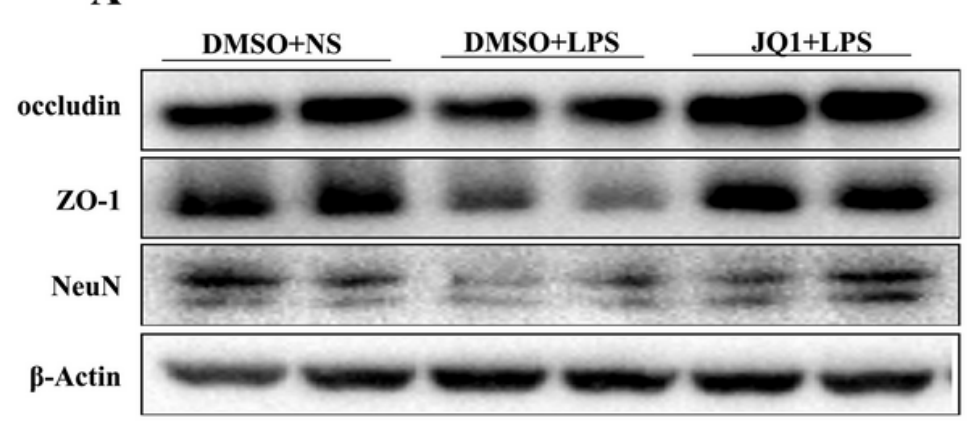

C

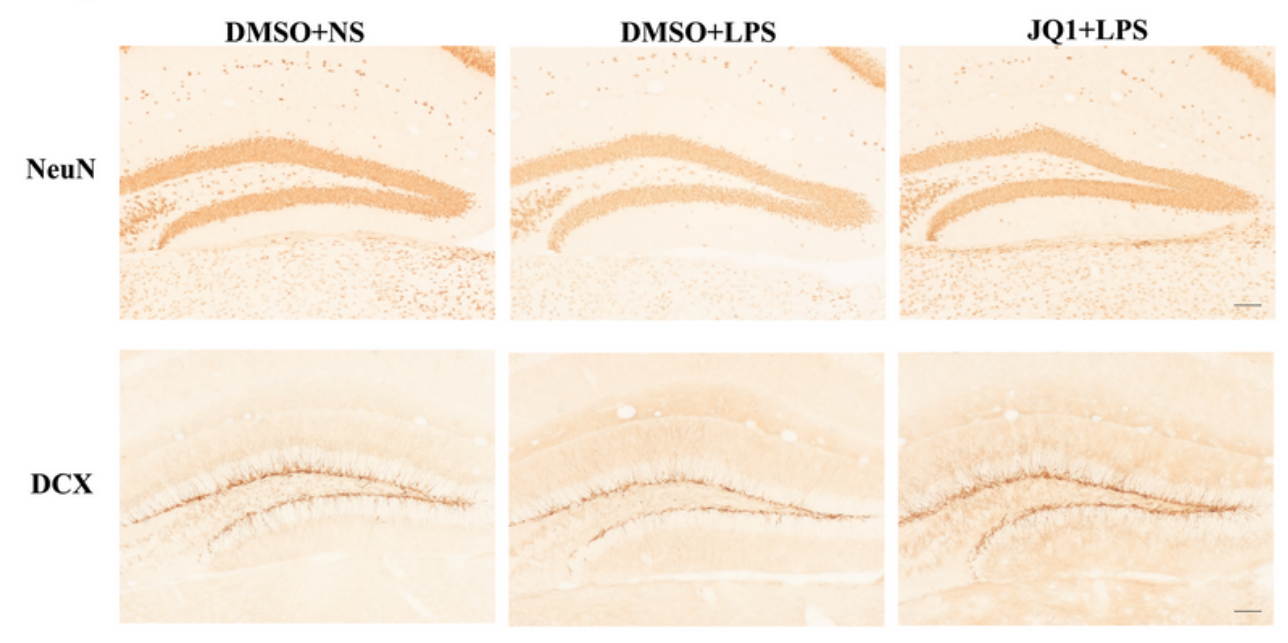

B

59 kDa

$220 \mathrm{kDa}$

46-55 kDa

$43 \mathrm{kDa}$

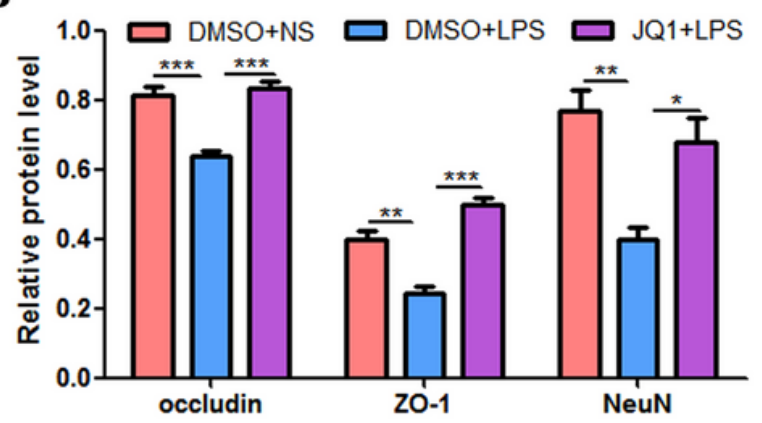

D

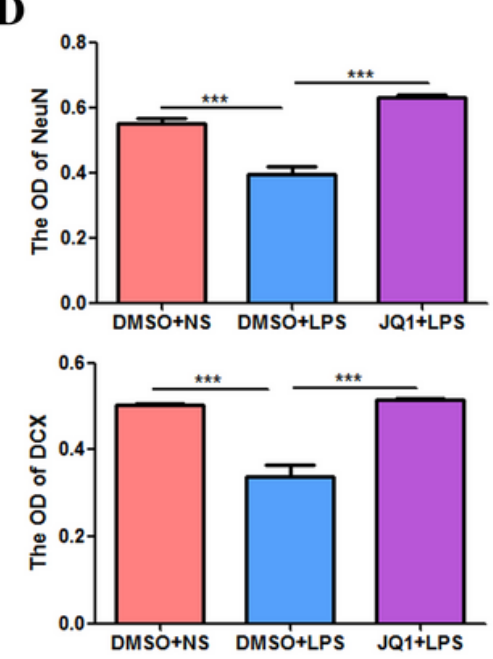

\section{Figure 5}

The effect of JQ1 on the neuronal and tight junction proteins in the hippocampus induced by LPS injection. (A) Representative western blotting immunolabeling of occludin, ZO-1 and NeuN and (B) semiquantitative analysis of occludin, ZO-1 and NeuN protein relative to $\beta$-Actin. (C) Representative immunohistochemistry images of NeuN and DCX positive cells and (D) quantitative analysis of the average optical density (OD) of NeuN and DCX in hippocampus for each group. Bar $=100 \mu \mathrm{m} . \mathrm{p}<0.05$ was considered significant, ${ }^{*} p<0.05$ and ${ }^{* *} p<0.01$. The results are shown as the mean $\pm S E M ; n=4-8$ animals in each experimental group. 